\title{
Effects of top leadership culture and strategic sustainability orientation on sustainable development among Malaysian herbal-based SMEs
}

\begin{abstract}
Entrepreneurial activities cause a disastrous effect on us and our future generation due to its contribution to environmental degradation. Because of this, sustainable entrepreneurship practice becomes a resolution of ecological problems capable of addressing business change issues, public health, and safety concerns and crucial for sustainable development. Pollution was identified causing environmental degradation among the upstream and downstream players in Malaysian herbal industry. In response, the Malaysian government focused on ensuring that herbal-based small and medium enterprises (SMEs) produce products through safe and environmentally friendly practices. Literature suggests that organizational culture influences sustainable entrepreneurship practice among small- and medium-sized enterprises, hence provide them the opportunities to achieve sustainable business development. Nonetheless, its implementation among SMEs is still low due to numerous challenges. This paper intends to investigate the standpoints of herbal-based SMEs on the influence of top leadership culture and strategic sustainability orientation on sustainable entrepreneurship practice towards achieving sustainable development. This study surveyed 300 herbal-based SMEs in Malaysia, and data were analyzed using structural equation model. Structural equation model displays the interrelations among latent constructs and observable variables in a model. The results show that top leadership culture has both direct and indirect effect on sustainable practices through strategic sustainability orientation, accounting for $71.049 \%$ variance. Findings reveal that both top leadership culture and strategic sustainability orientation are significantly related to sustainable entrepreneurship practice among the respondents, thus substantiates and support previous findings on the crucial roles of top leadership culture and strategic sustainability orientation in enabling organizations to achieve sustainable development.
\end{abstract}

Keyword: Herbal-based; Small and medium-sized enterprises; Strategic sustainability orientation; Sustainable development; Top leadership culture 